\title{
Geochemical evidence for bedding parallel oil migration in an inter-salt lacustrine shale oil reservoir
}

\author{
XiaOXiao Ma ${ }^{1}$, MaOWEN Li ${ }^{1}$, Menhui Qian ${ }^{1}$, Qigui \\ JIANG $^{1}$, ZHIMING LI ${ }^{1}$ \\ ${ }^{1}$ Sinopec Petroleum Exploration and Production Research \\ Institute, 31 Xueyuan Road, Beijing 100083, China \\ (*Correspondence: maxiaoxiao.syky@sinopec.com) \\ ${ }^{2}$ Sinopec Jianghan Oilfield Company, 18 Daxueyuan Road, \\ Gaoxin District, Wuhan, Hubei 430223, China
}

This study analyzes the bulk and molecular geochemical data of a continuous core samples of the Eocene Qianjiang Formation, a confined source rock unit embedded with salt intervals formed in a hypersaline lacustrine setting in central China. These source rocks within a single evaporative cycle collected from a recent shale oil exploration well are highly laminated, consisting of both intra- and inter-salt shales. Both organic pores and matrix pores serve as storage for hydrocarbon generated from kerogen within the source rock. Because the contrast in density between kerogen and oil, conversion of kerogen to oil inevitably leads to the increase in pore pressure and oil expulsion from kerogen within the same source rock unit. Impregnation of source rocks by expelled oils from nearby mature source rocks or from the organic-rich laminae within the same source rock units leads to anomalous Rock-Eval pyrolysis data, characterized by an abnormally high S1 peak, a high Production Index (PI), a suppressed Tmax and other anomalies. It is contradictory that both Rock-Eval pyrolysis data and sterane isomerization ratios of the studied inter-salt shale samples indicate strong impact of allochthonous hydrocarbons in the source rocks, whereas most aliphatic biomarker parameters obtained from the solvent extracts of these shales still provide useful information on the vertical variation in organic source input and depositional environment of the host rocks. The results suggest that oil migration occured mainly along bedding parallel planes and/or fissures, thus allowing the overprinting of geochemical signatures. This study provides insights into the bulk and molecular geochemical data interpretation, particularly in the inter-salt shale oil system evaluation in inferring the prevailing directions and pathways of diagenetic fluid movement and hydrocarbon migration. 